\title{
Comparison of Clinical and Radiologic Results of Mini-Open Transforaminal Lumbar Interbody Fusion and Extreme Lateral Interbody Fusion Indirect Decompression for Degenerative Lumbar Spondylolisthesis
}

\author{
Yutaka Kono, Hogaku Gen, Yoshio Sakuma, Yasuhide Koshika \\ Department of Orthopaedic Surgery, Chiba Central Medical Center, Chiba, Japan
}

\begin{abstract}
Study Design: Retrospective study.
Purpose: In this study, we compared the postoperative outcomes of extreme lateral interbody fusion (XLIF) indirect decompression with that of mini-open transforaminal lumbar interbody fusion (TLIF) in patients with lumbar degenerative spondylolisthesis.

Overview of Literature: There are very few reports examining postoperative results of XLIF and minimally invasive TLIF for degenerative lumbar spondylolisthesis, and no reports comparing XLIF and mini-open TLIF.

Methods: Forty patients who underwent 1-level spinal fusion, either by XLIF indirect decompression (X group, 20 patients) or by miniopen TLIF (T group, 20 patients), for treatment of lumbar degenerative spondylolisthesis were included in this study. Invasiveness of surgery was evaluated on the basis of surgery time, blood loss, hospitalization period, and perioperative complications. The Japanese Orthopedic Association Back Pain Evaluation Questionnaire (JOABPEQ), disc angle (DA), disc height (DH), and slipping length (SL) were evaluated before surgery, immediately after surgery, and at 12 months after surgery. Cross-sectional spinal canal area (CSA) was also measured before surgery and at 1 month after surgery.

Results: There was no significant difference between the groups in terms of surgery time or hospitalization period; however, $\mathrm{X}$ group showed a significant decrease in blood loss $(p<0.001)$. Serious complications were not observed in either group. In clinical assessment, no significant differences were observed between the groups with regard to the JOABPEO results. The change in DH at 12 months after surgery increased significantly in the $\mathrm{X}$ group $(p<0.05)$, and the changes in DA and SL were not significantly different between the two groups. The change in CSA was significantly greater in the T group $(p<0.001)$

Conclusions: Postoperative clinical results were equally favorable for both procedures; however, in comparison with mini-open TLIF, less blood loss and greater correction of DH were observed in XLIF.
\end{abstract}

Keywords: Lumbar osteoarthritis; Spinal stenosis; Spinal fusion; Minimally invasive surgery; Comparative effectiveness

Received May 18, 2017; Revised Jun 13, 2017; Accepted Jun 29, 2017

Corresponding author: Yutaka Kono

Department of Orthopaedic Surgery, Chiba Central Medical Center, 1835-1 Kasori-cho, Wakaba-ku, Chiba-shi, Chiba 264-0017, Japan Tel: +81-043-232-3691, Fax: +81-043-232-9100, E-mail: k.yutaka96@cb3.so-net.ne.jp 


\section{Introduction}

Recent advancements in minimally invasive spine surgery have been remarkable. In Japan, extreme lateral interbody fusion (XLIF) was introduced in 2013 and is rapidly gaining popularity. XLIF is a minimally invasive spinal fusion procedure that achieves interbody fusion using a retroperitoneal approach through the psoas major muscle and at the same time reducing the invasiveness of traditional anterior surgery. Because ligamentotaxis, in which a large cage spanning the width of the vertebral body is placed to restore the disc space height, provides indirect decompression of the neural elements and improved intervertebral stability, XLIF is considered highly effective for treating patients with degenerative lumbar spondylolisthesis who present with intervertebral instability and neurological symptoms $[1,2]$. In addition, by using XLIF in combination with percutaneous pedicle screw (PPS) fixation, lumber spinal fusion can be performed in the posterior lumbar muscles with the most minimal invasion.

On the contrary, transforaminal lumbar interbody fusion (TLIF) achieves interbody fusion via a unilateral approach, and is thus often applied to minimally invasive spinal fusion. Mini-open TLIF is a minimally invasive lumbar spinal fusion based on TLIF. It can reduce the invasiveness of surgery and the invasiveness to the paraspinal muscles by using a unilateral midline approach combined with the anatomical intermuscular approach reported by Wiltse and Spencer [3-5]. There are a few reports examining the postoperative results of XLIF and minimally invasive TLIF for degenerative lumbar spondylolisthesis [6,7], but none comparing XLIF and miniopen TLIF. The purpose of this study was to compare and examine postoperative clinical and radiologic results of indirect decompression and fusion using XLIF and those of mini-open TLIF performed for the treatment of degenerative lumbar spondylolisthesis.

\section{Materials and Methods}

This study was approved by the Institutional Review Board of Chiba Central Medical Center (IRB approval no., 18). We investigated 40 patients who underwent singlesegment fusion for degenerative lumbar spondylolisthesis that presented with pain in the lower legs, numbness, and intermittent claudication from 2012 to 2015. All patients were followed for at least 1 year. The inclusion criterion was surgery for central canal stenosis at L3-L4 or L4L5. The exclusion criteria were diagnoses of foraminal stenosis, reoperation, spinal tumor, infection, and fresh vertebral fracture. For clinical assessment, the Japanese Orthopedic Association Back Pain Evaluation Questionnaire (JOABPEQ) was administered before surgery and at 12 months after surgery, and the results were compared and evaluated. The JOABPEQ is a new evaluation scale based on self-administered outcomes developed by the Japanese Orthopedic Association. It is a useful evaluation tool, with verified reliability and validity. It consists of five domains (low back pain, lumbar function, walking ability, social life function, and mental health) and 25 evaluation
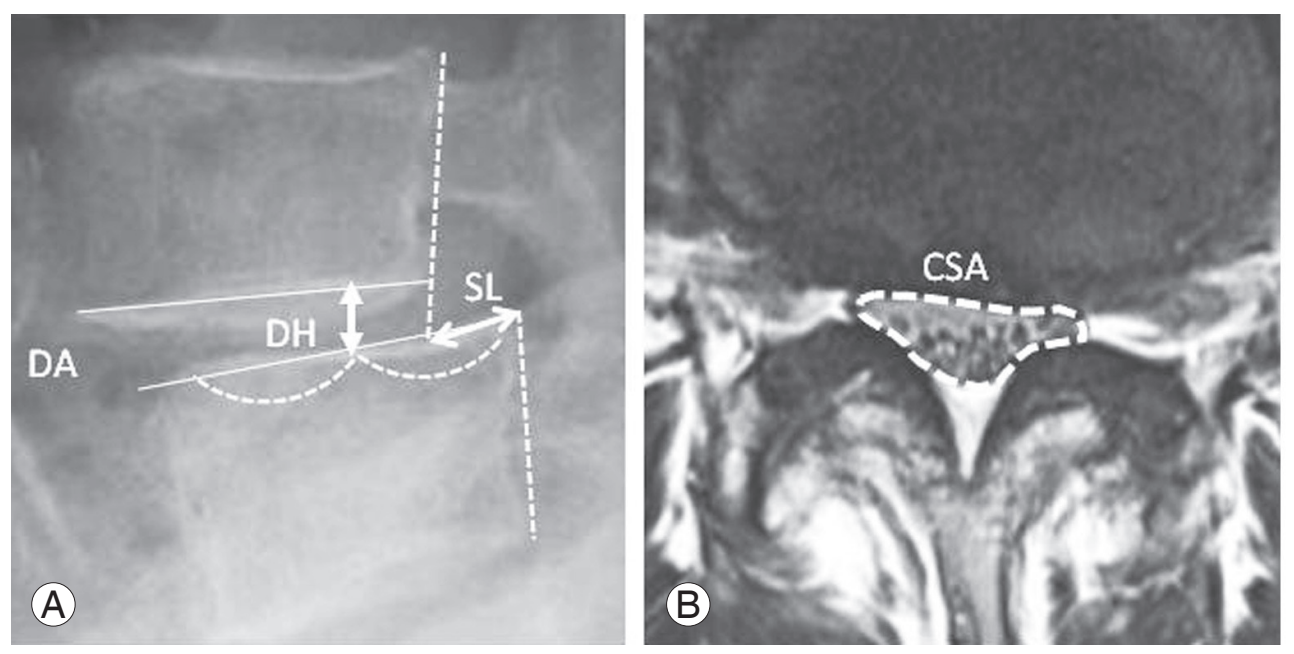

Fig. 1. (A) Upright plain lateral radiographs: disc angle (DA), disc height (DH), and slipping length (SL). (B) Magnetic resonance imaging-T2 axial: cross-sectional spinal canal area (CSA). 
items. The evaluation items are assessed for each domain, the highest score being 100; higher scores indicate better conditions [8]. The scores for each domain (postoperative score-preoperative score) were compared between the two groups to evaluate treatment effects. Invasiveness of surgery was evaluated on the basis of surgery time, volume of intraoperative blood loss, and hospitalization period. Perioperative complications and reoperation were also investigated. For radiological assessment, disc angle (DA), disc height (DH), and slipping length (SL) were measured before surgery, immediately after surgery, and at 12 months after surgery using upright plain lateral radiographs. The cross-sectional spinal canal area (CSA) was also measured for both procedures before surgery and at 1 month after surgery using magnetic resonance imaging T2WI (axial view), and the values were compared (Fig. 1). The average of image measurements determined by two examiners, including the authors, was taken into con- sideration.

\section{Surgical procedure}

In the XLIF procedure, the retroperitoneal space was accessed through the psoas major muscle by the mini-open technique, and a polyether ether ketone (PEEK) cage with a lordotic angle of $10^{\circ}$ was used as an interbody cage. One half each of autogenous iliac bone graft and synthetic bone graft (collagen hybrid) were placed in a cage. All patients underwent one-stage posterior spinal fusion using PPS fixation without direct decompression $[9,10]$ (Fig. 2A).

The mini-open TLIF was performed via a unilateral midline approach through a single longitudinal midline incision of approximately $5 \mathrm{~cm}$, and a unilateral facet was removed to secure the working portal. Neurological decompression was achieved bilaterally on the approach
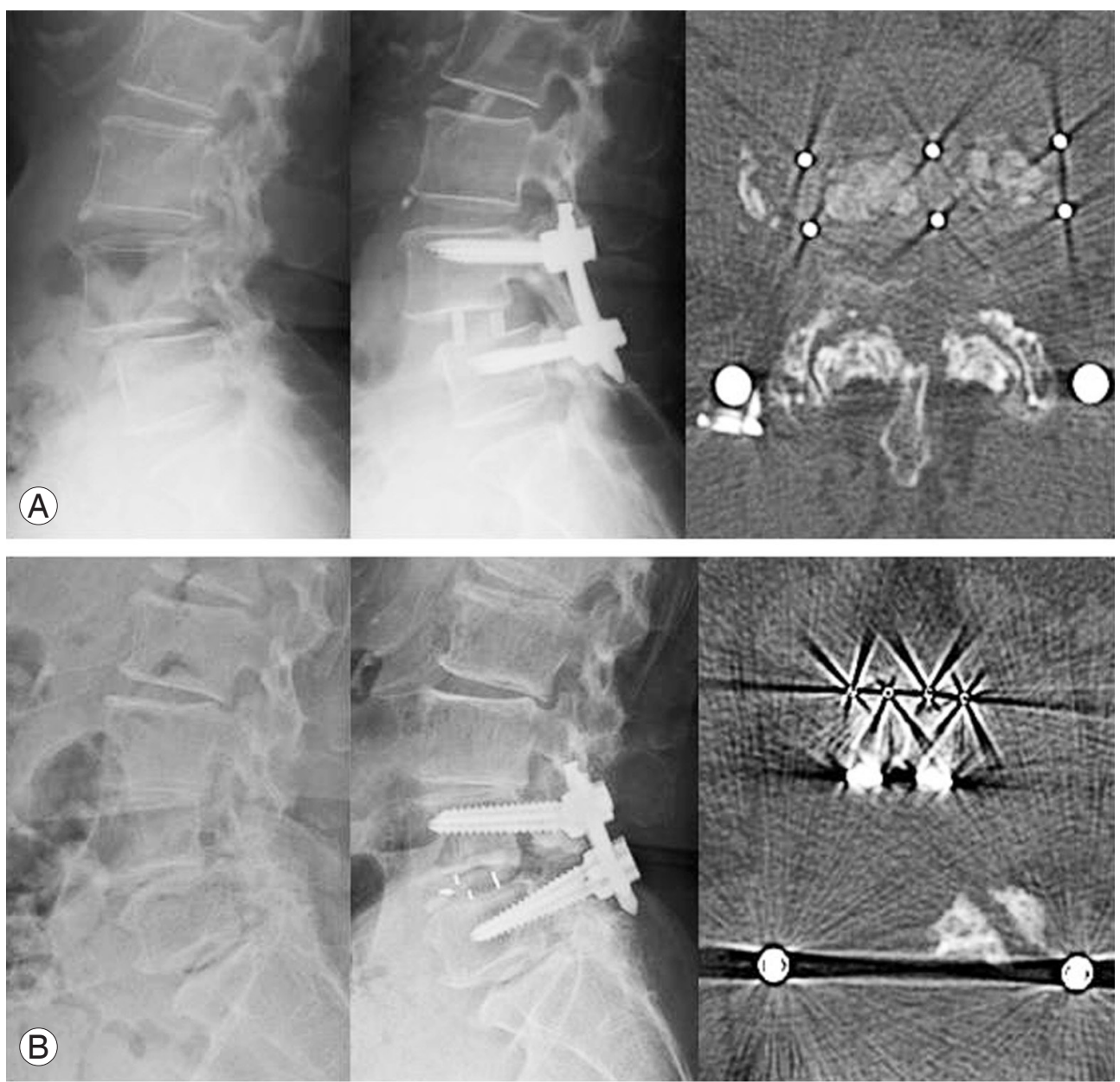

Fig. 2. Lateral radiographs before and after surgery and computed tomography scans after surgery. (A) Extreme lateral interbody fusion. (B) Mini-open transforaminal lumbar interbody fusion. 
side and unilaterally on the opposite side. After removing the intervertebral disc, a cage filled with local bone graft and local bone was placed in the disc space. Rectangular PEEK cages were used for the procedure. First, a cage was inserted obliquely toward the opposite side; then, the posterior portion of the cage was pushed contralaterally to place it parallel to the sagittal plane. A second cage was subsequently placed in the approach side [5]. Pedicle screws were bilaterally inserted using the anatomical intermuscular approach reported by Wiltse and Spencer [3], through the cleavage plane between the multifidus and longissimus muscles under direct vision with subcutaneous undermining and fasciotomy via the midline incision (Fig. 2B). Slip reduction was performed using a reduction screw in both groups. The heights of the cages were 8-10 $\mathrm{mm}$ for XLIF ( $8 \mathrm{~mm}$, three patients; $9 \mathrm{~mm}$, eight patients; $10 \mathrm{~mm}$, nine patients), and 7-9 $\mathrm{mm}$ for mini-open TLIF ( $7 \mathrm{~mm}$, six patients; $8 \mathrm{~mm}$, eight patients; $9 \mathrm{~mm}$, six patients).

\section{Statistical analysis}

Statistical analysis was performed using IBM SPSS Statistics ver. 23.0 (IBM Japan Ltd., Tokyo, Japan), and a $p$-value of less than 0.05 was considered statistically significant.

\section{Results}

The study subjects were 20 consecutive patients who had XLIF after November 2014 (X group: 10 males and 10 females; mean age, 69.9 years) and 20 patients who had mini-open TLIF before November 2014, all of whom underwent the same clinical and radiological evaluations as the patients who received XLIF (T group: seven males and 13 females; mean age, 66.2 years).Preoperative neurological symptoms were neurogenic claudication and radiculopathy in both groups (X group: nine cases and 11 cases, respectively and T group: 10 cases and 10 cases, respectively) (Table 1). During clinical assessment, patients in both the $\mathrm{X}$ and $\mathrm{T}$ groups showed significant improvement in terms of with their respective preoperative scores in all domains at 12 months after surgery (Fig. 3). No significant differences were observed between the two groups in terms of the JOABPEQ scores obtained before surgery and those obtained at 12 months after surgery (Table 2). In the assessment of surgery invasiveness, there was no significant difference in the mean surgery time (X group, 131.1 \pm 23.2 minutes; T group, $148.1 \pm 39.5$ minutes); however, the $\mathrm{X}$ group showed a significant decrease in the mean volume of blood loss (X group, $36.1 \pm 15.3 \mathrm{~mL}$; T group, $225.7 \pm 215.9 \mathrm{~mL} ; p<0.001)$. The hospitalization period was not significantly different between the two groups (X group, $14.6 \pm 7.5$ days; $\mathrm{T}$ group, $13.7 \pm 3.9$ days) (Table 3). Perioperative complications in the T group included dural tear in one patient (5\%), transient pain in the legs of two patients (10\%), and deep infection in one patient (5\%); no reoperations were performed. In the $\mathrm{X}$ group, thigh symptoms on the approach side were observed in eight patients (40\%), all of which resolved within 3 months after surgery, and pain in the contralateral thigh, probably due to hematoma and cage placement failure, was observed in two patients (10\%), which were relieved by conservative therapy. Serious complications were not observed in either group. One patient (5\%) in

Table 1. Preoperative demographic characteristics

\begin{tabular}{|c|c|c|c|}
\hline Characteristic & $X$ group & T group & $p$-value \\
\hline Age (yr) & $69.9 \pm 7.5$ & $66.2 \pm 8$ & $0.19^{\mathrm{a})}$ \\
\hline Male:female & $10: 10$ & $7: 13$ & $0.33^{\mathrm{bl}}$ \\
\hline Fusion level & & & $0.25^{c)}$ \\
\hline $\mathrm{L} 3 / 4$ & 6 & 3 & \\
\hline$\llcorner 4 / 5$ & 14 & 17 & \\
\hline Preoperative neurological symptoms & & & $0.75^{b)}$ \\
\hline Neurogenic claudication & 9 & 10 & \\
\hline Radiculopathy & 11 & 10 & \\
\hline
\end{tabular}

Values are presented as mean \pm standard deviation or number. $X$ group: extreme lateral interbody fusion group; T group: mini-open transforaminal lumbar interbody fusion group.

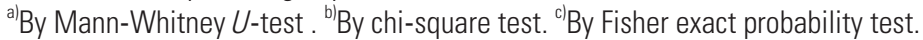



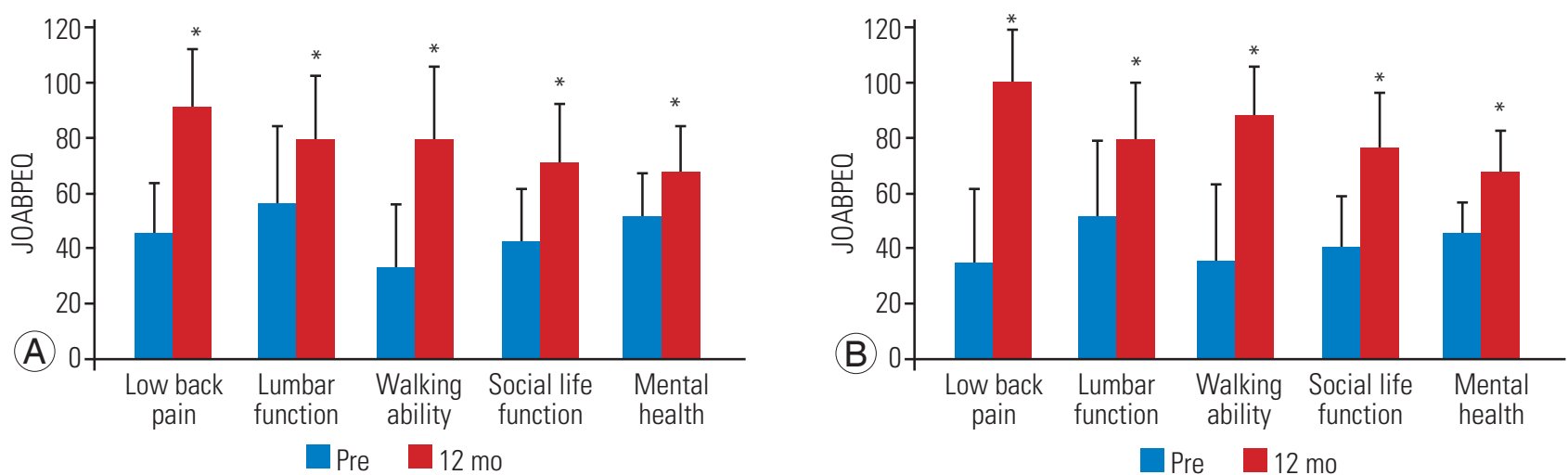

Fig. 3. Changes over time in JOABPEO. (A) X group: extreme lateral interbody fusion group. (B) T group: mini-open transforaminal lumbar interbody fusion group. JOABPEQ, Japanese Orthopedic Association Back Pain Evaluation Questionnaire; Pre, preoperative. " $p<0.05$ : significant improvement from preoperation (by Wilcoxon signed-rank test).

Table 2. Comparison of the Japanese Orthopedic Association Back Pain Evaluation Questionnaire

\begin{tabular}{|c|c|c|c|c|}
\hline Variable & Category & $X$ group & T group & $p$-value \\
\hline \multirow[t]{2}{*}{ Low back pain } & Pre & $45.1 \pm 19.1$ & $34.2 \pm 26.2$ & $0.13^{\mathrm{a})}$ \\
\hline & Pre $\rightarrow 12$ mo change & $47.3 \pm 21.1$ & $59.4 \pm 37.1$ & $0.25^{\text {b) }}$ \\
\hline \multirow[t]{2}{*}{ Lumbar function } & Pre & $56.2 \pm 28.2$ & $51.1 \pm 27.5$ & $0.23^{\mathrm{a})}$ \\
\hline & Pre $\rightarrow 12$ mo change & $22.5 \pm 33.3$ & $31.1 \pm 33.1$ & $0.45^{b)}$ \\
\hline \multirow[t]{2}{*}{ Walking ability } & Pre & $33.4 \pm 22.3$ & $35.2 \pm 28.4$ & $0.45^{\text {a) }}$ \\
\hline & Pre $\rightarrow 12$ mo change & $41.1 \pm 36.5$ & $59.1 \pm 28.2$ & $0.1^{\mathrm{b})}$ \\
\hline \multirow[t]{2}{*}{ Social life function } & Pre & $43.9 \pm 19.3$ & $39.5 \pm 18.7$ & $0.42^{\text {a) }}$ \\
\hline & Pre $\rightarrow 12$ mo change & $27.7 \pm 28.8$ & $37.7 \pm 30.1$ & $0.29^{\text {b) }}$ \\
\hline \multirow[t]{2}{*}{ Mental health } & Pre & $51.8 \pm 15.3$ & $44.4 \pm 12.1$ & $0.18^{a)}$ \\
\hline & Pre $\rightarrow 12$ mo change & $13.9 \pm 18.5$ & $19.7 \pm 22.6$ & $0.39^{\text {b) }}$ \\
\hline
\end{tabular}

Values are presented as mean \pm standard deviation. $X$ group: extreme lateral interbody fusion group; T group: mini-open transforaminal lumbar interbody fusion group.

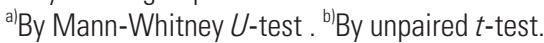

Table 3. Comparison of surgery invasiveness

\begin{tabular}{lccc} 
Variable & X group & Tgroup & p-value $^{\text {a) }}$ \\
\hline Surgical time (min) & $131.1 \pm 23.2$ & $148.1 \pm 39.5$ & 0.27 \\
Blood loss (mL) & $36.1 \pm 15.3$ & $225.7 \pm 215.9$ & $<0.001$ \\
\hline Hospital stay (day) & $14.6 \pm 7.5$ & $13.7 \pm 3.9$ & 0.87 \\
\hline
\end{tabular}

Values are presented as mean \pm standard deviation. $X$ group: extreme lateral interbody fusion group; T group: mini-open transforaminal lumbar interbody fusion group.

a)By Mann-Whitney U-test.

the $\mathrm{X}$ group required additional posterior decompression due to no improvement in symptoms (Table 4). As for the image measurements over time, the DA was significantly increased after surgery in the $\mathrm{X}$ group (from $5.1^{\circ}$ to $8.5^{\circ}$ to $8.3^{\circ}$ and was maintained even after 1 year; however, the
Table 4. Comparison of complications

\begin{tabular}{lccc} 
Variable & X group & T group & $p$-value \\
Major complication & 0 & 0 \\
Thigh symptom & $8(40)$ & 0 \\
\hline Transient pain in the legs & $2(10)$ & $1(5)$ \\
\hline Dural tear & 0 & $1(5)$ \\
Deep infection & 0 & $1(5)$ & \\
Reoperation & $1(5)$ & 0 \\
\hline Total & $10(50)$ & $3(15)$ & $<0.05$ \\
\hline
\end{tabular}

Values are presented as number or number (\%). X group: extreme lateral interbody fusion group; $T$ group: mini-open transforaminal lumbar interbody fusion group.

a) By Fisher exact probability test. 

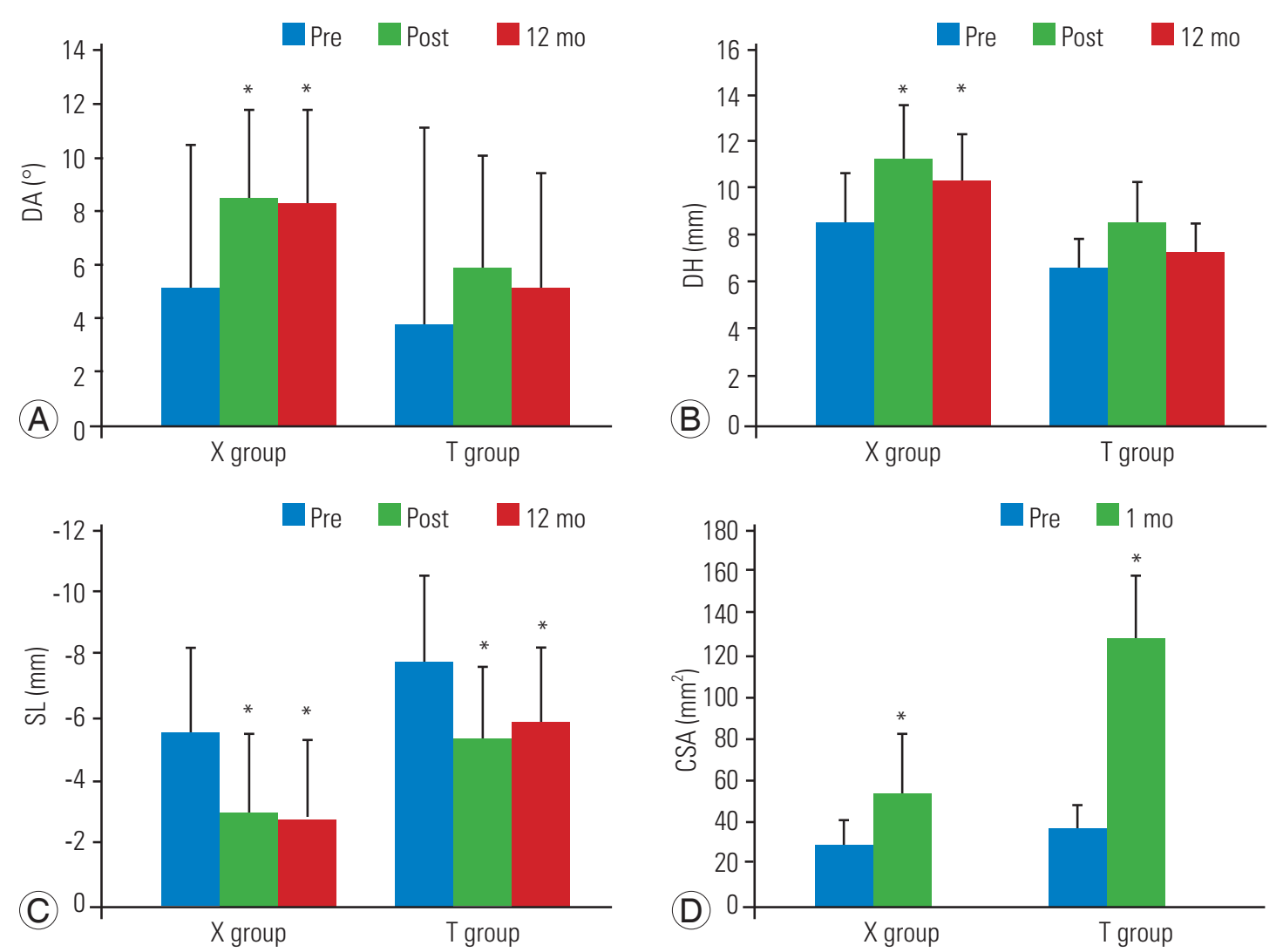

Fig. 4. Changes over time in image measurements. (A) Disc angle (DA), (B) disc height (DH), (C) slipping length (SL), and (D) cross-sectional spinal canal area (CSA). X group: extreme lateral interbody fusion group; T group: mini-open transforaminal lumbar interbody fusion group. Pre, preoperative; Post, postoperative. ${ }^{*} p<0.05$ : significant improvement from preoperation (by Wilcoxon signed-rank test).

improvement was not significant in the T group (from $3.7^{\circ}$ to $5.8^{\circ}$ to $\left.5.0^{\circ}\right)$. The $\mathrm{DH}$ was significantly increased after surgery in the X group (from 8.3 to 11.4 to $10.1 \mathrm{~mm}$ ) and was maintained until after 1 year; however, in the $\mathrm{T}$ group, although significant increase in DH was observed after surgery (from 6.4 to 8.6 to $7.1 \mathrm{~mm}$ ), there was no significant difference when the values determined before surgery and those determined at 1 year after surgery are compared. For SL, significant postoperative restoration was observed in both groups (from -5.5 to -3.1 to -2.8 $\mathrm{mm}$ in the $\mathrm{X}$ group and from -8.0 to -5.5 to $-6.0 \mathrm{~mm}$ in the $\mathrm{T}$ group), which was maintained until after 1 year. CSA was significantly larger after surgery in both groups (from 26.4 to $55.4 \mathrm{~mm}^{2}$ in the $\mathrm{X}$ group, and from 33.3 to $131.1 \mathrm{~mm}^{2}$ in the T group) (Fig. 4). When compared in terms of changes, significant differences were observed between the two groups in terms of DH, SL, and CSA measured before surgery, but no such difference was observed in DA. With regard to postoperative change, the change in DH at 12 months after surgery increased sig- nificantly in the $\mathrm{X}$ group than in the $\mathrm{T}$ group (X group, 1.8 $\mathrm{mm}$; T group, $0.7 \mathrm{~mm} ; p<0.05)$, and the changes in DA and SL were not significantly different between the two groups. The change in CSA was significantly greater in the T group (X group, $29 \mathrm{~mm}^{2}$; T group, $97.7 \mathrm{~mm}^{2} ; p<0.001$ ) (Table 5).

\section{Discussion}

During the XLIF procedure, indirect decompression of the neural elements and improved intervertebral stability can be achieved through ligamentotaxis, in which a large cage spanning the width of the vertebral body is placed to restore the disc space height $[1,2,11]$. Furthermore, XLIF does not require direct intervention to the nerve tissue or the epidural venous plexus, thereby reducing intraoperative blood loss [12]. On the other hand, mini-open TLIF is a minimally invasive posterior lumbar fusion in which neurological decompression and the TLIF technique are performed via a unilateral midline approach. Here, pedi- 
Table 5. Comparison of DA, DH, SL, and CSA

\begin{tabular}{|c|c|c|c|c|}
\hline Variable & Category & $X$ group & T group & $p$-value ${ }^{\mathrm{a})}$ \\
\hline \multirow[t]{3}{*}{$\mathrm{DA}\left({ }^{\circ}\right)$} & Pre & $5.1 \pm 5.5$ & $3.7 \pm 7.2$ & 0.58 \\
\hline & Pre $\rightarrow$ post change & $3.4 \pm 4.7$ & $2.1 \pm 5.3$ & 0.41 \\
\hline & Pre $\rightarrow 12$ mo change & $3.2 \pm 4.3$ & $1.3 \pm 5.3$ & 0.26 \\
\hline \multirow[t]{3}{*}{$\mathrm{DH}(\mathrm{mm})$} & Pre & $8.3 \pm 2.6$ & $6.4 \pm 1.6$ & $<0.05$ \\
\hline & Pre $\rightarrow$ post change & $2.4 \pm 3.1$ & $2.2 \pm 1.7$ & 0.21 \\
\hline & Pre $\rightarrow 12$ mo change & $1.8 \pm 1.9$ & $0.7 \pm 1.4$ & $<0.05$ \\
\hline \multirow[t]{3}{*}{$\mathrm{SL}(\mathrm{mm})$} & Pre & $-5.5 \pm 2.9$ & $-8.0 \pm 2.8$ & $<0.05$ \\
\hline & Pre $\rightarrow$ post change & $-2.3 \pm 1.6$ & $-2.4 \pm 2$ & 0.92 \\
\hline & Pre $\rightarrow 12$ mo change & $-2.5 \pm 1.8$ & $-1.9 \pm 2$ & 0.29 \\
\hline \multirow[t]{2}{*}{$\mathrm{CSA}\left(\mathrm{mm}^{2}\right)$} & Pre & $26.4 \pm 10.3$ & $33.3 \pm 11$ & $<0.05$ \\
\hline & Pre $\rightarrow 1$ mo change & $29 \pm 19.1$ & $97.7 \pm 26.7$ & $<0.001$ \\
\hline
\end{tabular}

Values are presented as mean \pm standard deviation. $\mathrm{X}$ group: extreme lateral interbody fusion group; T group: mini-open transforaminal lumbar interbody fusion group.

$\mathrm{DA}$, disc angle; DH, disc height; SL, spondylolisthesis; CSA, cross-sectional spinal canal area.

${ }^{a}$ By Mann-Whitney U-test .

cle screws are inserted bilaterally using an intermuscular approach, resulting in less blood loss compared with conventional methods and a simultaneously reduction in the invasiveness to the paraspinal muscles.

The invasiveness assessment indicated intraoperative blood loss in XLIF to be less than that in mini-open TLIF. This is because direct decompression of the spinal canal was not performed in XLIF, which may have reduced bleeding from the epidural venous plexus. On the other hand, surgery time and hospitalization period were comparable for XLIF and TLIF. The hospitalization period tends to be longer in Japan than in Europe and the United States because, under the health insurance system in Japan, patients often remain hospitalized for treatment including rehabilitation for postoperative ambulation.

Although indirect decompression achieved by XLIF is reported to significantly increase CSA after surgery $[1,2]$, the increase rate is considered smaller than that observed after TLIF [6]. In this study, a significant increase in CSA was also observed after XLIF, but the change was smaller than that after mini-open TLIF with direct decompression. However, both procedures showed similar improvement in postoperative clinical results based on the JOABPEQ. The improvement observed in the $\mathrm{X}$ group is presumably attributed to indirect neurological decompression achieved by XLIF and a synergistic effect with high interbody stability. Thus, XLIF is considered to be a highly effective, minimally invasive procedure for degen- erative lumbar spondylolisthesis with neurological symptoms and intervertebral instability.

Several reports compared lumbar spinal alignment after fusion by XLIF and conventional TLIF, reporting significant postoperative improvement in segmental lordosis and $\mathrm{DH}$ in both procedures; however, the increase in $\mathrm{DH}$ observed after XLIF was greater than that observed after TLIF $[13,14]$. Isaacs et al. [6] investigated the change in alignment 2 years after XLIF and minimally invasive TLIF for low grade degenerative spondylolisthesis, and reported that although DH was significantly restored in both procedures, correction loss was observed after minimally invasive TLIF. Likewise, many articles reported that XLIF was superior to TLIF for correcting DH and the results of this study validate the same.

Incidence of perioperative complications is relatively low at $8.8 \%-16.6 \%$ for conventional TLIF and 3.3\%-18.7\% for minimally invasive TLIF. Although intraoperative dural tears are relatively more common than XLIF, the incidence of serious complications is reportedly low [15-17]. As XLIF is performed through the psoas major muscle, thigh symptoms, such as neurological symptoms in the lower extremities caused by injury or traction onto the lumbar plexus, and transient muscle weakness caused by contusion of the psoas major muscle, may occur immediately after surgery, and the incidence of these symptoms is often reported to be high (23\% to $67 \%)[18,19]$. However, many of the symptoms are transient, and Cummock et al. 
[18] reported that $50 \%$ were resolved in 3 months after surgery and $90 \%$ in 1 year after surgery. In XLIF, serious complications such as damage to the blood vessels and/or organs associated with the retroperitoneal approach were also reported [20], and it is essential to acquire anatomical knowledge and carefully analyze preoperative images.

The results of the study demonstrated that, after XLIF, blood loss was lesser and $\mathrm{DH}$ correction greater than that achieved by mini-open TLIF for degenerative lumbar spondylolisthesis. Thus, XLIF is a highly effective treatment for the elderly and in cases requiring intervertebral correction. However, XLIF is usually not recommended for the L5-S1 disc due to the risk of injury to the blood vessels or for spondylolisthesis of grade II or higher (Meyerding classification) due to issues related to the location of the cage. It should also be performed with caution for rising psoas (i.e., the psoas muscle rising away from the lateral aspect of the vertebral body) because of the risk of injury to the lumbar plexus $[1,2,21]$. The clinical indications for indirect decompression remain unclear; however, it is usually not recommended for intervertebral joint degeneration without intervertebral mobility, bony stenosis, disc herniation extending through the posterior longitudinal ligament, and intraspinal facet cysts [1]; minimally invasive posterior lumbar decompression and fusion using mini-open TLIF is considered useful in such cases.

Since this is a retrospective study with limitations including small sample size, short follow-up period, and the existence of significant differences in preoperative radiologic data between $\mathrm{X}$ group and $\mathrm{T}$ group further investigation is necessary.

\section{Conclusions}

Postoperative results were compared and examined between patients who underwent single-segment fusion using mini-open TLIF and XLIF, which are minimally invasive lumbar fusion procedures for the treatment of degenerative lumbar spondylolisthesis. Postoperative clinical results were equally favorable for both procedures; however less blood loss and greater correction of $\mathrm{DH}$ were observed after XLIF than after mini-open TLIF. Although XLIF is an effective and minimally invasive procedure for degenerative lumbar spondylolisthesis, surgical procedures should be selected after careful consideration of various issues, including complications and clinical indications.

\section{Conflict of Interest}

No potential conflict of interest relevant to this article was reported.

\section{References}

1. Oliveira L, Marchi L, Coutinho E, Pimenta L. A radiographic assessment of the ability of the extreme lateral interbody fusion procedure to indirectly decompress the neural elements. Spine (Phila Pa 1976) 2010;35(26 Suppl):S331-7.

2. Elowitz EH, Yanni DS, Chwajol M, Starke RM, Perin NI. Evaluation of indirect decompression of the lumbar spinal canal following minimally invasive lateral transpsoas interbody fusion: radiographic and outcome analysis. Minim Invasive Neurosurg 2011;54:201-6.

3. Wiltse LL, Spencer CW. New uses and refinements of the paraspinal approach to the lumbar spine. Spine (Phila Pa 1976) 1988;13:696-706.

4. Lee DY, Jung TG, Lee SH. Single-level instrumented mini-open transforaminal lumbar interbody fusion in elderly patients. J Neurosurg Spine 2008;9:137-44.

5. Taneichi H, Suda K, Kajino T, Matsumura A, Moridaira H, Kaneda K. Unilateral transforaminal lumbar interbody fusion and bilateral anterior-column fixation with two Brantigan I/F cages per level: clinical outcomes during a minimum 2-year follow-up period. J Neurosurg Spine 2006;4:198-205.

6. Isaacs RE, Sembrano JN, Tohmeh AG; SOLAS Degenerative Study Group. Two-year comparative outcomes of MIS lateral and MIS transforaminal interbody fusion in the treatment of degenerative spondylolisthesis: part II: radiographic findings. Spine (Phila Pa 1976) 2016;41 Suppl 8:S133-44.

7. Sembrano JN, Tohmeh A, Isaacs R; SOLAS Degenerative Study Group. Two-year comparative outcomes of MIS lateral and MIS transforaminal interbody fusion in the treatment of degenerative spondylolisthesis: part I: clinical findings. Spine (Phila Pa 1976) 2016;41 Suppl 8:S123-32.

8. Fukui M, Chiba K, Kawakami M, et al. JOA Back Pain Evaluation Questionnaire (JOABPEQ)/JOA Cervical Myelopathy Evaluation Questionnaire (JOACMEQ): the report on the development of revised versions; April 16, 2007; the Subcommittee of 
the Clinical Outcome Committee of the Japanese Orthopaedic Association on Low Back Pain and Cervical Myelopathy Evaluation. J Orthop Sci 2009;14:34865.

9. Ozgur BM, Aryan HE, Pimenta L, Taylor WR. Extreme Lateral Interbody Fusion (XLIF): a novel surgical technique for anterior lumbar interbody fusion. Spine J 2006;6:435-43.

10. Yson SC, Sembrano JN, Santos ER, Luna JT, Polly DW Jr. Does prone repositioning before posterior fixation produce greater lordosis in lateral lumbar interbody fusion (LLIF)? J Spinal Disord Tech 2014;27:364-9.

11. Castellvi AE, Nienke TW, Marulanda GA, Murtagh $\mathrm{RD}$, Santoni BG. Indirect decompression of lumbar stenosis with transpsoas interbody cages and percutaneous posterior instrumentation. Clin Orthop Relat Res 2014;472:1784-91.

12. Rodgers WB, Gerber EJ, Rodgers JA. Lumbar fusion in octogenarians: the promise of minimally invasive surgery. Spine (Phila Pa 1976) 2010;35(26 Suppl):S355-60.

13. Sembrano JN, Yson SC, Horazdovsky RD, Santos ER, Polly DW Jr. Radiographic comparison of lateral lumbar interbody fusion versus traditional fusion approaches: analysis of sagittal contour change. Int J Spine Surg 2015;9:16.

14. Watkins RG 4th, Hanna R, Chang D, Watkins RG 3rd. Sagittal alignment after lumbar interbody fusion: comparing anterior, lateral, and transforaminal approaches. J Spinal Disord Tech 2014;27:253-6.
15. Brodano GB, Martikos K, Lolli F, et al. Transforaminal lumbar interbody fusion in degenerative disk disease and spondylolisthesis grade I: minimally invasive versus open surgery. J Spinal Disord Tech 2015;28:E559-64.

16. Shunwu F, Xing Z, Fengdong Z, Xiangqian F. Minimally invasive transforaminal lumbar interbody fusion for the treatment of degenerative lumbar diseases. Spine (Phila Pa 1976) 2010;35:1615-20.

17. Lee KH, Yue WM, Yeo W, Soeharno H, Tan SB. Clinical and radiological outcomes of open versus minimally invasive transforaminal lumbar interbody fusion. Eur Spine J 2012;21:2265-70.

18. Cummock MD, Vanni S, Levi AD, Yu Y, Wang MY. An analysis of postoperative thigh symptoms after minimally invasive transpsoas lumbar interbody fusion. J Neurosurg Spine 2011;15:11-8.

19. Grimm BD, Leas DP, Poletti SC, Johnson DR 2nd. Postoperative complications within the first year after extreme lateral interbody fusion: experience of the first 108 patients. Clin Spine Surg 2016;29:E151-6.

20. Assina R, Majmundar NJ, Herschman Y, Heary RF. First report of major vascular injury due to lateral transpsoas approach leading to fatality. J Neurosurg Spine 2014;21:794-8.

21. Kepler CK, Sharma AK, Huang RC, et al. Indirect foraminal decompression after lateral transpsoas interbody fusion. J Neurosurg Spine 2012;16:329-33. 